\title{
Improving learning environments through whole-school collaborative action research
}

Jill M. Aldridge, Paul E. Rijken \& Barry J. Fraser

\begin{abstract}
The focus of professional learning on activities has changed to internal growth or change among teachers. Our three-year whole-school collaborative action research was based on student feedback from a learning environment survey at a secondary school. Quantitative data were obtained by administering a survey in 2012, 2013 and 2014 to 2673 students in 171 classes to assess perceptions of the learning environment. Qualitative information, involving classroom observations and interviews with the principal and professional development coordinator, illuminated how the school incorporated this collaborative action research approach. Statistically-significant differences for numerous aspects of the learning environment were found between the 2012, 2013 and 2014 student groups.
\end{abstract}

Keywords Collaborative action research, learning environment, professional development, school improvement, self-efficacy, whole-school approach

\section{Introduction}

Because teacher professional development is widely viewed as central to school improvement, a large proportion of the budget of schools and education systems is invested in it (Akibo 2013; Mourshed and Barber 2007; OECD 2011). Although schools continue to rely heavily on formal activities and training events as the chief means of developing teachers, criticisms of these approaches have led to a shift in our understanding of teachers' role in professional development, the need for relevant learning, the importance of teachers 
being active participants in the learning process, and the realities that teachers face (Avalos 2011; Broad and Evans 2006; Levin and Rock 2003). These recognitions have led to a paradigm shift from professional development to development of the professional (Bubb and Earley 2008; Evans 2014) and the emergence of approaches to professional development such as experiential learning (Girvan, Conneely, and Tangney 2016), Quality Teaching Rounds (Bowe and Gore 2016), shared practice (Holloway and Long 2006) and social networking (Kelly and Antonio 2016; Macià and García 2016). These approaches support learner-centred views of teaching that are largely grounded in reflection, inquiry and participant-driven experimentation and provide impetus for teachers to initiate change (Dean 2006).

In this study, we investigated the use of collaborative action research as an approach to teacher learning that involves this paradigm shift. In investigating the effectiveness of collaborative action research in a whole-school improvement effort, our research foci were:

- how the school established a culture of collaborative action research over the three years

- whether a whole-school approach involving the use of student feedback is effective in improving the learning environment.

Action research and collaborative action research

The use of action research as a tool for professional development and improving classroom learning is not new (e.g., Carr and Kemmis 1983; Kemmis and McTaggart 1988). Numerous studies have highlighted the benefits for teachers-as-researchers to focus on teaching practices and skills in their own classrooms (Aldridge, Fraser, Bell and Dorman 2012; Aldridge, Fraser and Sebela 2004; Bell and Aldridge 2014; Hu, Torres and Feng 2019). Action research, according to Carr and Kemmis (1983), involves cycles of self-critical and 
reflective processes when teachers learn about their own classroom environments and their teaching practices. An important element of teacher action research is the reflection stage during which teachers have the opportunity to consider their own teaching practices in order to find solutions to issues that need to be addressed (Fullan 1999). Teachers' involvement in action research, particularly when related to their personal teaching strategies and skills, provides a valuable form of professional growth (Carr and Kemmis 1983).

Collaborative action research is a form of action research that involves professionals working together on research to improve their teaching practice. As with action research, collaborative action research requires teachers to adopt a critical, self-reflective and systematic approach to assessing their teaching contexts. However, unlike action research, collaborative action research involves teachers engaging with colleagues during systematic and reflective implementation of their practices as a means of generating meaningful knowledge that is relevant to the teaching situation and the challenges that teachers face (Hine 2013; Manesi and Betsi 2013). Collaborative action research recognises the central role of teachers in decision making by being situated in the specific needs and conditions of students and schools (McTaggert, 1997; Pellrin and Paukner 2015; Rock and Levin 2002; Yang 2019). Further, because collaborative action research provides teachers with a means for initiating change (rather than being told to teach differently), it is potentially transformative (Dean 2006).

Teachers' involvement in action research in a collaborative school environment has been found to have a measurable and direct impact on student achievement, behaviour and equity, as well as the performance of colleagues and school leaders (Reeves 2008). Research suggests that teachers are more deeply committed to examining, evaluating and questioning their practice when they share their teaching practice. Therefore, collaborative action research has the potential to open between-teacher communicative channels that can be used to 
investigate and challenge the pedagogical practices and beliefs that underpin teaching strategies (Kijkuakul 2019; Pellerin 2011). The empowering nature of collaborative action research has a potentially transformative impact on instructional practice, making it highly applicable to professional development (Nelson 2013; Ross and Bruce 2012; West 2011).

Collaborative action research can involve different formats that represent a continuum from teams working together on different topics (with a shared single focus) to teams working together on a single study (West 2011). As an approach to professional development, these levels of involvement in the collaborative process make it applicable to a wide range of contexts.

In the study reported in this article, collaborative action research focused on the work of individual teachers as a means of bringing about whole-school change, especially in how teachers were engaged in reflection about and approaches to improving their practice. Although collaborative action research is associated with positive impact on professional development (e.g. Bleicher 2014), numerous factors can affect the efficacy of collaborative action research in schools, such as: the rigour or quality of the action-research approach (Glanz 2016; Hewitt and Little 2005; Ross and Bruce 2012); the school context (Glanz 2016; Hahs-Vaughn and Yanowitz 2009; West 2011); the team dynamics within the school (Galini and Efthymia 2010; Peterson et al. 2008; Simeon 2015); and teachers' motives for participating (Mug`alog`lu and Dog`anca 2009; Pellerin and Paukner 2015). As part of this study, we examined how collaborative action research was introduced at the school level in ways that attempted to address these factors.

A central component of collaborative action research is critical self-reflection, or reflection both in action and on action (Pellerin and Paukner 2015). When teachers are given space and time to improve their reflection behaviours and reflect on their practices, they are more likely to fashion new beliefs and become creators of knowledge (Banegas et al. 2013). 
Through reflection and dialogue with peers, teachers are given opportunities to examine areas in which their practices might not address the context-specific needs of students (Kasi 2010) and consider inconsistencies in their actions, feelings and thoughts - leading to an awaress of the need to change their practice. In this study, we investigated how teachers used students' feedback about the learning environment as a means of reflection during collaborative action research.

Field of learning environments: students' perspectives in collaborative action research

The research reported in this article drew on the field of classroom learning environments, which provides a rich array of extensively-used and comprehensively-validated questionnaires for assessing students' perceptions of their classroom environments (Fraser 2012, 2014, 2019). In particular, the approach followed in our current research evolved gradually from the five-step procedure of action research, originally proposed by Fraser (1981) and subsequently adapted based on action research studies carried out since this time (e.g., Aldridge, Fraser and Sebela 2004; Bell and Aldridge 2014). These steps (assessment and feedback; reflection and focusing; planning; implementing and refining; and reassessment) are described later in this article.

The field of learning environments was shaped by Lewin (1936), who proposed that personal behaviour is a result of the interaction between the individual and his/her environment, and Murray (1938), who proposed that an individual's behaviour is affected internally by characteristics of personality (needs) and externally by the environment (press). Later, the notion of person-environment fit was further elucidated by Hunt (1975) and Stern (1970). 
The use of participants' perceptions in learning settings was pioneered independently in the US by Walberg and Anderson (1968), who developed the Learning Environment Inventory for research on Harvard Project Physics, and Moos and Trickett (1974), whose development of the Classroom Environment Scale linked extensive prior work in other human environments to school settings. This initial research on classroom environment then spread to the Netherlands (Wubbels and Levy, 1993) and Australia (Fraser, 1990).

A major focus in classroom environment studies around the world over the past 40 years has been research that has consistently replicated associations between students' cognitive and affective learning outcomes and their perceptions of psychosocial characteristics of their classroom environments (Fraser 2012, 2014). Another major application of learning environment questionnaires has been as a source of process criteria of effectiveness in the evaluation of educational innovations (e.g. Chipangura and Aldridge 2017; Lightburn and Fraser 2007; Zaragoza and Fraser 2017). The focus of the present article is how teachers used feedback information as a basis for guiding practical improvements in classrooms (e.g. Aldridge and Fraser 2008; Aldridge, Fraser and Sebela 2004).

\section{Research methods}

Ethics approval to collect data was granted by a university and the relevant school system prior to the commencement of the study. At all stages, considerations were made to ensure compliance with ethical standards. All participant provided informed consent prior to the collection of data.

The study used a mixed-method approach which combined quantitative data collected from a student classroom learning environment survey with qualitative information from school documents, interviews with administrative staff and classroom observations. Data 
collection involved a sequential design in which qualitative information gathered over three years provided insights into findings derived from quantitative data. Quantitative data were gathered at the end of each of the three years. This section describes research methods, instruments used to collect quantitative and qualitative data, and the sample involved each year.

Learning environment scales and their original source

At the end of each of the three years of the study, an instrument called the Classroom Climate Questionnaire (CCQ) was administered to assess students' perceptions of their learning environment. The CCQ contains 11 scales based on existing learning environment scales that previously have been extensively validated. Table 1 lists the name of each CCQ scale that we chose and adapted from five existing learning environment questionnaires and provides the original source and a description for each scale.

Table 1 about here

Six scales in Table 1 (Student Cohesiveness, Teacher Support, Equity, Involvement, Task Orientation and Collaboration) are from the What Is Happening In this Class? (WIHIC, Aldridge, Fraser and Huang 1999), which currently is the world's most-frequently used learning environment questionnaire according to Dorman (2008) and Fraser (2019). Recently, Skordi and Fraser (2019) tabulated details of 28 major studies that used the WIHIC in 15 different countries and 8 languages in addition to English: Arabic, Indonesian, Korean, Myanmar, Chinese, IsiZulu (South Africa), Greek and Spanish. Khine et al. (2018) tabulated 24 studies in 12 countries that had cross-validated and used the WIHIC. Similarly, Fraser 
(2019) listed 21 studies that cross-validated and used the WIHIC in 13 countries and 12 languages. Using confirmatory factor analysis with data from 3980 high-school students from Canada, the UK and Australia, Dorman (2003) supported the WIHIC's multi-scale structure. Also Dorman (2008) used multitrait-multimethod modelling with data from 978 secondary students to further support the construct validity of the WIHIC.

One scale in Table 1, namely, Young Adult Ethos, is from the TROFLEI (TechnologyRich Outcomes-Focused Learning Environment Inventory). The TROFLEI was initially developed by Aldridge and Fraser (2008) to monitor the evolution of the learning environments in a new alternative high school with an outcomes-focus and an emphasis on using technology, but subsequently has been validated in numerous studies undertaken in Israel (Magen-Nagar and Steinberger 2017), Australia (Aldridge, Dorman and Fraser 2004; Aldridge et al. 2012), New Zealand (Koul et al. 2011), Turkey (Cakir 2011; Welch et al. 2012) and the USA (Earle and Fraser 2018; Welch et al. 2012).

Two scales related to the assessment of student learning and informing learners of their progress (Formative Assessment, Clarity of Assessment) were selected from the Constructivist-Orientated Learning Environment Survey (COLES, Aldridge, Fraser, Bell and Dorman 2012; Bell and Aldridge 2014). The COLES originally was validated using exploratory factor analysis with 2043 grade 11 and 12 students in 9 Australian schools. As well, a simplified version of the CCQ containing 45 items in 9 scales was validated with a sample of 609 Australian primary-school students.

The Personal Relevance scale in Table 1 is from the Constructivist Learning Environment Survey (CLES, Taylor, Fraser and Fisher 1997). The CLES has been validated and used in studies in Korea (Kim, Fisher and Fraser 1999), Texas (Nix, Fraser and Ledbetter 2015), Ohio (Partin and Haney 2012), South Africa (Aldridge, Fraser and Sebela 2004) and Singapore (Koh and Fraser 2014). 
The Differentiation scale was adapted from the Individualised Classroom Environment Questionnaire (ICEQ; Fraser 1990; Fraser and Butts 1982), which was the first learning environment questionnaire to focus on student-centred classrooms. The ICEQ has been cross-validated in numerous studies and been used to investigate associations between the nature of the classroom learning environment and student outcomes (Fraser and Fisher 1982) and the school-level environment (Fraser and Rentoul 1982).

Rationale for choosing each learning environment scale

In this section, we justify our selection of each of the 11 scales in Table 1 . It is important that the learning environment created by teachers is supportive in order to provide students with appropriate intellectual, social and physical conditions for effective learning. Students are more likely to learn if they feel accepted and free from harassment or prejudice from the teacher or peers. First, Student Cohesiveness was chosen to assess the extent to which students know, help and support each other. To make sure that the environment is supportive of student learning, teachers need to create policies and practices to help students feel that they are accepted and supported by peers (Curriculum Council 1998) and can make mistakes without risking ridicule. Social acceptance by peers and the need to have friends are important aspects that can affect students' learning.

Second, Teacher Support was selected to assess the extent to which the teacher helps, relates to, trusts and is interested in students. The teacher's relationship with students is pivotal because it can lead students to love or hate a subject and to be inspired or turned away from learning. The supportiveness of a teacher gives students the courage and confidence to tackle new problems, take risks in their learning, and persist to complete challenging tasks. If students consider that a teacher is approachable and interested in them, they are more likely 
to seek help if there is a problem. The teacher's relationship with students is integral to student success and to creating a collaborative learning environment (Hijzen et al. 2007).

Because the learning environment should provide opportunities for all the students in the class (Rennie 2004, 2005), the Equity scale was chosen to assess the extent to which students perceive that teachers encourage and include them as frequently as their peers. This scale gives an indication of whether students perceive that they are being treated fairly by the teacher.

Also, because this study was carried out in a senior school environment, it was important to assess the extent to which students are encouraged to be responsible for their own learning (Aldridge and Fraser 2008). Therefore, the Young Adult Ethos scale was selected to assess whether students feel that teachers give them responsibility and treat them as young adults.

Although the nature of student assessment is a critical dimension of the learning environment, nearly all classroom environment questionnaires exclude this aspect. Information about assessment is critical so that teachers know how students are performing academically and how best to support them in the classroom (Allen et al. 2009). The Formative Assessment scale assesses the extent to which students feel that assessment tasks are part of the learning process, rather than a separate summative process conducted at the end of the learning journey, and contribute positively to learning. Formative assessment practices provides opportunities for students to discuss their progress with teachers and engage in peer-assessment and self-assessment as ways of monitoring and reflecting on their learning. If students are able to recognise the link between their learning and assessment, assessment becomes educative, contributes positively to student learning, enables students to plan for future learning and fosters self-directed learning practices. 
The Clarity of Assessment Criteria scale was chosen to assess the extent to which assessment criteria are explicit, clear and public in order to support and enhance teachers' ability to make professional judgements about student learning and allow students to know the criteria used when they are assessed. This provides a powerful means of improving student learning by making clear the goals towards which students are striving, providing useful feedback, encouraging reflection on current understandings, and enabling planning for success in future learning (O’Donovan et al. 2004).

Research suggests that, when students are actively involved in learning activities, learning is more meaningful (Curriculum Council 1998). Involvement was selected to assess the extent to which students feel that they have opportunities to participate in discussions and have attentive interest in the classroom. The Involvement scale assumes that language plays an important part in helping students to understand what they are learning (Taylor and Campbell-Williams 1993) and that giving students the opportunity to participate in classroom discussions and to negotiate ideas and understandings with peers, rather than listening passively, are important aspects of the learning process.

Another important principle is that students need to have goals, both short-term and long-term, to provide motivation and purpose (Killen 2001; Spady 1994). If goals are clear and relevant, students are more likely to be engaged in their learning. Coupled with the need for meaningful goals is the need to have clear expectations and frequent feedback and reinforcement to ensure that students' time-on-task is optimised. To assess the extent to which students perceive that it is important to complete activities and understand goals, the Task Orientation scale was selected.

To ensure that students engage in their learning, it is necessary for teachers to make the content relevant to the students' lives outside school (Taylor et al. 1997) and provide 
meaningful contexts when introducing new knowledge. The Personal Relevance scale was chosen to assess the connectedness of a subject with students' out-of-school experiences.

It is desirable that teachers encourage collaborative learning environments in which students work together to find solutions to problems (Johnson et al. 2007; Lin and Burbules 1993; Tan et al. 2007). Whilst it is acknowledged that students should be given opportunities to work as individuals, it is equally important that they work together collaboratively. Because learning experiences should include opportunities for students to collaborate with and learn from each other, the Collaboration scale was selected.

Because students differ in terms of their abilities, rates of learning and interests (Griffin and Smith 1997; Spady 1993), it is desirable for teachers to provide different students with learning experiences that cater for this diversity. The Differentiation scale was included to assess the extent to which students perceive that teachers cater for students differently based on their capabilities and interests.

Assembling the CCQ

Although the original scale names and underlying constructs remained largely the same in the CCQ, subtle changes to items were made to ensure their relevance to classroom teachers. For example, although the original Student Cohesiveness scale referred to friendship groups, it was more pertinent to assess whether students feel safe and accepted by their peers in the learning environment (regardless of whether they had friends in the class). For example, the item "Members in this class are my friends" was changed to "I feel supported by students in this class". In addition, for economy, the number of items originally in each scale (usually 8 items) was reduced to 6 items. 
All 11 CCQ scales are oriented towards student-centred learning environments and fall into three main domains: relationships (with the scales student cohesiveness, teacher support, equity, and young adult ethos), assessment practices (with the scales of formative assessment and clarity of assessment criteria) and delivery of lessons (with the scales of involvement, task orientation, personal relevance, collaboration, and differentiation).

CCQ items are responded to using a five-point frequency response scale: Almost Never, Seldom, Sometimes, Often and Almost Always. Student feedback, provided through the CCQ, was used by teachers as part of collaborative action research involving examining the extent to which the classroom learning environment perceived by students is congruent with students' preferences. The CCQ involves a side-by-side response format that enables students to provide information not only about the learning environment that is present (actual environment) but also the learning environment that they would like to be present (preferred environment). Figure 1 provides an example of the side-by-side response format.

Figure 1 about here

We retained the original positive wording of all items in the chosen scales because past studies have shown that this improves response accuracy and internal consistency (Schriesheim, Eisenbach and Hill 1991; Schriesheim and Hill 1981). Each scale contains 8 items, that are grouped together in a block rather than arranged randomly or cyclically, in order to provide contextual prompts, reduce confusion among students and ensure response assertiveness (Aldridge, Fraser, Taylor and Chen 2000).

Qualitative information 
To examine how the school established a culture of collaborative action research over the three years of the study, qualitative information was gathered from the principal of the school (who supported and oversaw the implementation of the approach) and the school's director of curriculum (who assisted with the implementation of the collaborative action research and supported team leaders and teachers during this process). This information included unstructured (discussion-style) interviews with the principal (recorded as field notes) and notes recorded by the director of curriculum. In addition, the teachers involved in the process wrote reflection journals that highlighted each stage of the process. Many of these journals were viewed by the principal (as part of teachers' annual work progress reporting) and teachers were invited to share their results and reflection journals with the researchers.

Sample

The sample was drawn from one school which used student feedback in three-year collaborative action research aimed at improving the school. To evaluate whether the collaborative action research was effective in terms of improving students' perceptions of the learning environment, quantitative data were collected at the end of each school year using the CCQ. Surveys were administered to students in one class of each teacher involved in the study (and selected by the teacher). In the first year, 28 teachers volunteered to be involved, providing a sample of 498 students. In the second year, based on positive feedback from the 28 volunteers, 66 teachers became involved, providing a sample of 1252 students. Finally, in the third year of the study, 77 teachers were involved, providing a sample 923 students.

Because teachers were not guided in their selection of classes, many teachers each year opted for a more-challenging class. The selected classes were from across all grade levels (years 8 to 12) in all three years of the study. 
When Cronbach's alpha reliability coefficient was calculated for each scale of the revised CCQ for this study's sample of 2673 students, satisfactory scale reliabilities ranging from 0.87 to 0.94 were obtained. Table 1 provides and the alpha coefficient for each CCQ scale.

\section{Results}

Developing a whole-school approach using student feedback

The whole-school approach to collaborative action research was introduced over six key stages which were important for building trust within the school, particularly within the collaborative action research groups. The first stage, when teachers were invited to become involved, involved trying out the process with a smaller group of teachers and promoting buy-in among other teachers. At this stage, we concentrated on building trust across the school community so that teachers were assured that their results would not be divulged and that the collaboration would be carried out in a non-threatening environment. Twelve teacher volunteers were involved in using a five-step process (described below).

The second stage involved building on the momentum and success from the initial group of teachers who used student feedback and strategies for improving learning environments. The teachers involved in step one shared their experiences and insights with members of the staff (at whole-group staff meetings and as show-cases). Feedback from these teachers highlighted a number of challenges that were encountered during the process (such as a lack of time) and these were addressed by the school in two ways.

First, it was decided that students would be released from school early once a week to make time for teachers to engage effectively in the process. This provided time for weekly 
team meetings when teachers engaged in professional discussions about the collaborative action research. During these collaborative meetings, a process of critical self-reflection, based on the student feedback, was encouraged and possible strategies and interventions were discussed. During the week, teachers implemented strategies that were discussed and decided upon during the meeting and they critically reflected on their actions. Second, to acknowledge the value of the process as part of professional development, the school permitted the time spent on the collaborative action research to count as professional development hours towards their teachers' registration requirements at the end of the year.

Encouraged by the support of the school and stories of improvements relayed by teachers, the number of volunteers more than doubled in the second year to 66 teachers. The process for these teachers was similar to stage 1, involving a modified five-step process, but collaborative groups of approximately five teachers were formed to formalise the collaborative nature of the action research in an effort to improve the effectiveness of the process. At the end of the second year, teachers were again encouraged to show-case their research and share their findings with other teachers in the school.

In the third stage (year 3 of the study), all teachers at the school were involved in the five-step collaborative action research process (described below). During this stage, teachers were divided into curriculum teams which were not based on the learning area, but were designed to provide a forum for discussion about learning and teaching and learning environments. The teams were led by curriculum leaders (appointed by the school at the end of the second stage) who were responsible for facilitating the meetings. The leaders of each team were provided with professional development to help them to effectively engage teachers in discussions and data analytics and about effective teaching practice and pedagogy. Importantly, these teams moved away from questions about what should be taught to the how it should be taught. 
In the fourth stage, a person was employed to coordinate the processes and observe classrooms. Protocols for the effective use of classroom observations were developed using a collaborative process that involved all staff members.

In the fifth stage, two teachers (in addition to the curriculum leader) were trained as classroom observers/coaches so that all teachers could be observed during the intervention phase of their action research. To further leverage the strategies and skills used by teachers to improve their learning environment, teachers were asked to become involved in disseminating their findings during short staff workshops that focused on specific dimensions of the learning environment.

In addition to these stages, feedback from collaborative meetings, classroom observations and aggregated learning environment data for all classes) were used to guide decisions about the whole-school focus for teacher professional development. For example, because aggregated scores on the Differentiation scale in 2013 were relatively low compared with the other scales, an educational consultant with expertise in the differentiation of instruction came to the school and delivered a workshop to all staff. Teachers were asked to link their individual professional development requests to their student feedback. Line managers and mentors, in the third year, also used student feedback data as a means of initiating professional conversations with staff about their professional development. As a result, during each of the three years, different scales became the foci for whole-school professional development.

Teachers' use of student feedback - collaborative action research

Integral to the school improvement process was teachers' involvement in the collaborative action research process. Field notes and teacher-written reflection journals indicated that, in 
each year of the study, a five-step process was used to improve the learning environment of individual classrooms.

1. Assessment and feedback. In the first step, teachers administered the CCQ to assess students' perceptions of the learning environment in one or more of their classes. Feedback, based on students' responses (involving their perceptions of both the perceived or actual learning environment and their preferred learning environment) was provided to teachers. These steps are outlined below together with vignettes (Yin 2011) to illustrate each step. These impressionistic tales from the field (van Maanen 1988) provide the reader with insights into how the data might be used in a classroom setting. Although based on the analysis of a range of journals written by teachers, these vignettes follow the actions of one teacher, Lily (pseudonym).

Lily, a teacher with four years of teaching experience, decided that the focus of her action research would be a year 8 geography class that was studying landscapes and landforms. Students' responses to the CCQ for this teacher are portrayed in Figure 2, which provides a graphical representation of students' perceptions of the actual learning environment and their preferred learning environment.

Figure 2 about here

2. Reflection and focusing. In the second step, the teachers reflected on the feedback. Reflections and discussions with colleagues in their collaborative action research group were used to identify which aspect(s) of the learning environment might become the focus for change. Guided by a group leader, teachers collaborated with each other in closely examining the data and interpreting their feedback in light of their classroom context. 
During these sessions, individual strengths (related to what students viewed as positive aspects of their environments) were celebrated and the collective efficacy of the group was helpful when examining ways in which individual practice could be improved. The following vignette describes Lily's reflection and decision based on feedback from students.

After reflecting on the data and discussing her results with colleagues (and with her students), Lily selected three dimensions on which she would focus her attention (Involvement, Personal Relevance and Differentiation). This decision was influenced by the scores reported by students, the size of the actual-preferred gap, and her ability to make a difference in these areas. She also hypothesised that these areas might impact on students' enjoyment of her lessons (which she noted was relatively low).

3. Planning. This step involved developing a working plan for teachers' intervention and included:

a. Working collaboratively to develop working hypotheses that might help to explain the current issue or challenge related to selected focus areas.

b. Considering what was needed (in terms of knowledge about the focus area) to develop a working plan. For teachers at this school, this involved examining their own 'teaching toolbox' (what did they know about this area of weakness already that they were not using in their practice), working with or observing other teachers who were performing well in the area of focus, learning from an external expert or engaging in professional reading.

c. Developing a plan for action that would guide the intervention intended to improve the area of focus. Teachers' plans for action varied considerably, depended on the focus for change, were implemented over one school term, and involved achievable 
lines of action. In the vignette below, a description is given of Lily's decisions about how to improve the learning environment dimensions identified in the previous step.

Lily decided that, to address all three focus areas, she would change how she planned to conduct the unit. First, to improve Personal Relevance, she included an excursion to a local river to reinforce the unit content (landscapes and landforms). Second, she designed a task requiring students to redesign a part of the river area to include aspects that would be interesting to teenagers and environmentally friendly (Relevance). During the task, students would be permitted to choose with whom they would work and the artefact that they would create (Differentiation and Involvement).

4. Implementing and refining. Teachers implemented the intervention for 6-10 weeks when they constantly reflected, both in (during) action and on (after) action, as a basis for refining the intervention. To help with the reflections, the group leader observed each class and helped through questioning techniques. The vignette below briefly describes Lily's experiences.

Lily reflected and refined her plan throughout the intervention period and made adjustments, such as intervening when self-selected groups were not productive and providing ideas for students when they were unsure about the artefacts that they would create.

5. Reassessment. The CCQ was re-administered to students at the end of the intervention period to determine whether they perceived their learning environment differently from before and to help teachers to evaluate the effectiveness of their interventions. Importantly, 
at this stage, the school provided a forum for teachers to present their research in order to share learning and encourage other teachers to participate. The following vignette includes posttest results and Lily's opinions about the collaborative action research.

When Lily re-administered the survey, the feedback profile portrayed in Figure 3 was generated to show pretest results for actual and preferred scores, as well as posttest results for actual and preferred scores. In addition to improvements in her target areas (Involvement, Relevance and Differentiation), Figure 3 also shows improvements in other areas. Regarding the process, Lily reported: "This process guided my personal development. It provided me with areas to focus on ... [and helped me] to design strategies that were built around the needs of the class. I also used the opportunity to work collaboratively with other staff ... to brainstorm and share ideas which helped to broaden our thinking."

Figure 3 about here

Effectiveness of using student feedback to improve the learning environment

To answer our research question concerning the effectiveness of teacher action research, the 2012, 2013 and 2014 groups were compared in terms of their classroom learning environment scores using multivariate analysis of variance (MANOVA). This analysis involved only students' perceptions of the actual version of the CCQ (i.e. what was actually occurring in the classroom) as opposed to their preferences. When preliminary assumption testing was used to examine normality, linearity and univariate and multivariate outliers, no serious violations were detected. For the combined set of 11 dependent variables, MANOVA revealed a 
statistically-significant difference between year groups, $F(24,5318)=20.37, p=0.000$; Wilks' lambda $=0.84$; partial eta squared $=0.08$.

Gauging the effectiveness of using student feedback by comparing the three year groups should be considered preliminary because our study was not strictly longitudinal in the sense that all of the same students were present in 2012, 2013 and 2014. A small proportion of students left the school each year and a small proportion of new students arrived at the school each year. Because the proportions of students leaving and arriving each year was quite small, it is likely that the three year groups were highly similar and therefore probably provided a fair basis for comparison. Nevertheless, we prefer to characterise our analyses as preliminary and advise caution when interpreting findings.

Because the multivariate MANOVA yielded statistically significant differences between year groups for the set of dependent variables as a whole, the univariate ANOVA was interpreted separately for each of the 11 learning environment as reported in Table 2. This table provides each dependent variable's average item mean (i.e. scale mean divided by the number of items) and average item standard deviation, as well as the ANOVA results ( $F$ values) for each scale for differences between 2012, 2013 and 2014 groups.

Table 2 about here

Table 2 shows a clear pattern in which scale mean scores generally were higher in 2013 than in 2012 and higher in 2014 than 2013. The univariate ANOVA results indicate that differences between the three year groups were statistically significant $(p<0.01)$ for students' perceptions of the learning environment for 8 of the 11 CCQ scales.

To identify which between-group differences were statistically significant, Tukey's HSD multiple comparison procedure was conducted as reported in Table 3. In this table, 
effect sizes (Cohen's $d$ ) are provided as estimates of the magnitude of differences between each pair of groups (i.e. 2012 group vs. 2013 group, 2013 group vs. 2014 group, and 2012 group vs. 2014 group). These effect sizes in Table 3 range from small to medium according to Cohen's (1988) criteria. Although generally not large, the differences between year groups in Table 3 are in a consistent direction and therefore can be considered to be practically important as discussed below

Table 3 about here

Comparison between the 2012 and 2013 groups also should be made with caution because the sample sizes for the two groups varied (because of the voluntary nature of the process). Nevertheless, scores for the 2013 group were statistically-significantly higher $(p<0.05)$ for six scales: Young Adult Ethos (effect size $=0.15$ standard deviations); Formative Assessment (effect size $=0.15)$; Clarity of Assessment Criteria $($ effect size $=$ 0.15); Task Orientation (effect size $=0.12)$; Personal Relevance $($ effect size $=0.15)$ and Differentiation (effect size $=0.19$ standard deviations) .

Comparing the 2013 and 2014 groups revealed significantly-higher scores in 2014 for the following six of the $11 \mathrm{CCQ}$ scales: Formative Assessment (effect size $=0.11$ standard deviations); Clarity of Assessment Criteria (effect size $=0.15)$; Involvement (effect size $=$ 0.19); Personal Relevance (effect size $=0.14)$; Collaboration $($ effect size $=0.16$ standard deviations); and Differentiation (effect size $=0.22$ standard deviations).

Across the three years of the study (2012 group vs. 2014 group), there were statistically-significantly higher scores for seven scales: Young Adult Ethos (effect size = 0.19 standard deviations); Formative Assessment (effect size $=0.25$ ); Clarity of Assessment 
Criteria (effect size $=0.28)$; Involvement $($ effect size $=0.29)$; Task Orientation $($ effect size $=$ 0.19); Personal Relevance (effect size $=0.28$ ); and Differentiation (effect size $=0.39$ ).

\section{Discussion}

Since the time when Fraser (1981) initially proposed a simple strategy for teacher action research aimed at improving classrooms and classroom environments by using actual and preferred forms of classroom environment questionnaires, this idea took root slowly and sporadically around the world until it achieved the significant international uptake reviewed by Fraser and Aldridge (2017). In the book entitled Student Voice: Teacher Action Research and Classroom Improvement, Bell and Aldridge (2014), describes successful contemporary approaches to improving classroom learning environments through teacher action research. In the whole-school improvement attempt reported in this article, we investigated the process of implementing collaborative action research and its impact on the classroom environment.

Developing a whole-school approach to collaborative action research

In this collaborative action research, it took three years to achieve buy-in from all teachers, which is consistent with much past research on resistance to teacher change (e.g. Helsing, Howell and Lahey 2008; Smith 2005). We tackled this resistance by setting aside school time when teachers not only could meet to discuss and plan improvements to practice, but also to become involved in professional development in coaching and mentoring and develop as leaders of collaborative action research groups. These actions sent teachers a message about the importance of the process to the school, while peer-led team meetings helped to encourage less-willing teachers. For other schools struggling with teacher buy-in, we 
recommend providing time for teachers to plan and meet together regularly to discuss progress.

This collaborative action research was driven largely by the principal and was accompanied by changes in school norms, with both administrative staff and teachers becoming change agents. The importance of the principal in guiding the values of the school in terms of change efforts is widely documented (e.g. Fullan 2001; Leithwood and Day 2002; Leo and Wickenberg 2013). Over the three years, teachers' views of collaborative action research shifted from suspicion about additional work to accepting it as part of the job of teaching. This change in norms meant that teachers were more willing to be involved and viewed the process as beneficial to both themselves and learners. It is recommended that future action research focuses on changing norms over time.

Building trust among teachers, which is important when introducing collaborative action research, involved gradually drawing on volunteers from within the school. The process was facilitated by providing teachers with time for collaboration and planning and recognising this involvement as part of professional development requirements. Having a forum for teachers to disseminate their findings improved buy-in from future volunteer teachers and encouraged teachers in subsequent attempts. Building trust as a component of collaboration is important (Devlin-Scherer and Sardone 2013; Herbert and Rainford 2014).

The evolving nature of the collaborative action research was sensitive to the needs of teachers and helped to avoid undue demands. Addressing these pressures and making collaborative action research part of the professional norms of the school helped teachers to communicate regularly. The allocation of time for regular teacher meetings helped to establish an environment in which reciprocal interaction could take place. The need for these opportunities has been highlighted by Lampi, Dimino and Taylor (2015) and providing them has been recommended by Cambridge, Kaplan and Suter (2005). 
Using learning environment feedback as part of collaborative action research

Statistical analysis of data from our classroom environment questionnaire revealed significant differences between 2012, 2013 and 2014 groups for seven learning environment scales: young adult ethos, clarity of assessment criteria, involvement, task orientation, personal relevance and differentiation. Students' perceptions of the learning environment and were statistically-significantly more positive for the groups in later years, thereby tentatively supporting the efficacy of using learning environment feedback as part of whole-school collaborative action research. A degree of caution is needed in interpreting these results because the three year groups, although highly similar, might not have been completely comparable.

Although effect sizes generally were relatively small according to Cohen's rule of thumb, differences between 2012, 2013 and 2014 groups were in the same direction and still can be considered to be practically significant. Changes in schools, particularly cultural changes, are time-consuming, difficult and challenging (Reeves 2007; McLeskey and Waldron 2006) and can take several years (Fullan 2007). Mobilising all staff to become involved in collaborative inquiry required teachers' buy-in and willingness to critically examine what they were doing in the classroom. Such change can bring about improved student outcomes and also be maintained over time (DuFour, DuFour, Eaker and Many 2006; Waldron and McLeskey 2010).

Apparently, a learning environment focus was non-threatening, which is consistent with past research (e.g. Aldridge, Bell, Fraser and Dorman 2012). Using student feedback in collaborative action research encouraged teachers' critical self-reflection about strategies for improving their learning environment and appeared to encourage change. The marked 
increase in the number of volunteer teachers suggests that collaborative action research became part of the school culture and that teachers became increasingly self-reflective as part of their work.

Incorporating collaboration into the process of action research increased professional interactions and conversations within curriculum teams and around the school, thereby reducing the silo effect, increasing social and professional capital and contributing to sustained change. Our study replicates Pellerin's (2011) finding that, when interactions between teachers increase, they are more likely to question and evaluate their classroom actions and beliefs and transform their practices.

Changes experienced at the school could be attributable to involvement in collaborative action research generating critical self-reflection in this social context, which can have transformative effects on learning (Hobbs and Coiro 2016; Ngcoza and Southwood 2015) and overcome subconscious resistance to change, especially sustained change (Bowe, Lahey, Armstrong, and Kegan 2003). The school is embedding collaborative action research as part of its culture and creating a community of practice (Cambridge, Kaplan and Suter 2005) through regular interaction between teachers. Overall, our study provides further insights into potentially-effective strategies for improving learning environments and adds weight to past research (Bell and Aldridge 2014; Fraser and Aldridge 2017) that suggests that collaborative action research in teachers' professional learning can be transformative and lead to school improvement.

Acknowledgements: This work was supported by the Australian Government under the Students First Support Fund. 


\section{References}

Akibo, M. (Ed.). (2013). Teacher reforms around the world: Implementations and outcomes. Bradford, UK: Emerald.

Aldridge, J. M., Dorman, J. P., \& Fraser, B. J. (2004). Use of multi-trait-multi-method modelling to validate actual and preferred forms of the Technology-Rich OutcomesFocused Learning Inventory (TROFLEI). Australian Journal of Educational and Developmental Psychology, 4, 110-125.

Aldridge, J. M., \& Fraser, B. J. (2008). Outcomes-focused learning environments: Determinants and effects (Advances in Learning Environments Research series). Rotterdam: Sense Publishers.

Aldridge, J. M., Fraser, B. J., Bell, L., \& Dorman, J. P. (2012). Using a new learning environment questionnaire for reflection in teacher action research. Journal of Science Teacher Education, 23, 259-290.

Aldridge, J. M., Fraser, B. J., \& Huang, I. T. C. (1999). Investigating classroom environments in Taiwan and Australia with multiple research methods. Journal of Educational Research, 93, 48-62.

Aldridge, J. M., Fraser, B. J., \& Sebela, M. (2004). Using teacher action research to promote constructivist learning environments in South Africa. South African Journal of Education, 24, 245-253.

Aldridge, J. M., Fraser, B. J., Taylor, P. C., \& Chen, C. C. (2000). Constructivist learning environments in a cross-national study in Taiwan and Australia. International Journal of Science Education, 22, 37-55. 
Aldridge, J.M., \& Galos, S. (2018). Development and validation of an instrument to assess primary school students' perceptions of the learning environment. Learning Environments Research, 21(3), 349-368.

Allen, D., Ort, S.W., \& Schmidt, J. (2009). Supporting classroom assessment practice: Lessons from a small high school. Theory into Practice, 48, 72-80.

Avalos, B. (2011). Teacher professional development in teaching and teacher education over 10 Years. Teaching and Teacher Education, 27, 10-20.

Banegas, D., Pavese, A., Velázquez, A., \& Vélez, S. M. (2013). Teacher professional development through collaborative action research: Impact on foreign Englishlanguage teaching and learning. Educational Action Research, 21(2), 185-201.

Bell, L. M., \& Aldridge, J. M. (2014). Student voice, teacher action research and classroom improvement (Advances in Learning Environments Research series). Rotterdam: Sense Publishers.

Bleicher, R.E. (2014). A collaborative action research approach to professional learning, Professional Development in Education, 40 (5), 802-821.

Bowe, C. M., Lahey, L., Armstrong, E., \& Kegan, R. (2003). Questioning the "big assumptions" part I: Addressing personal contradictions that impede professional development. Medical Education, 37(8), 715-722.

Bowe, J., \& Gore, J. (2016). Reassembling teacher professional development: The case for Quality Teaching Rounds. Teachers and Teaching: Theory and Practice, 23(3), 352366.

Broad, K., \& Evans, M. (2006). A review of literature on professional development content and delivery modes for experienced teachers: Report for the Ontario Ministry of Education. Toronto: University of Toronto.

Bubb, S., \& Earley, P. (2010). Helping staff develop in schools. London: Sage. 
Cakir, M. (2011). Validity and reliability of the Turkish form of Technology-Rich OutcomeFocused Learning Environment Inventory. Kuram Uygulamada Egit. Bilim, 11(4), 1959-1963.

Cambridge, D., Kaplan, S., \& Suter, V. (2005). Community of practice design guide: A stepby-step guide for designing and cultivating communities of practice in higher education. Retrieved from http.//net.educause.edu/ir/library/pdf/nli0531.pdf

Carr, W., \& Kemmis, S. (1983). Becoming critical: Knowing through action research. Geelong, Australia: Deakin University.

Chipangura, A., \& Aldridge, J. M. (2017). Examining the impact of multimedia on students' perceptions of the learning environment. Learning Environments Research, 20(1), 121-138.

Cohen, J. (1988). Statistical power analysis for the behavioral sciences (2nd ed.). Hillsdale, NJ: Lawrence Erlbaum Associates.

Curriculum Council. (1998). Curriculum framework. Perth: Curriculum Council of Western Australia.

Dean, B. L. (2006). Action research: A viable alternative for in-service teacher professional development. In S. Ali and M. Rizvi (Eds.), Quality in education: Teaching and leadership in challenging times (pp. 129-155). Karachi: Aga Khan University, Institute for Educational Development.

Devlin-Scherer, R., \& Sardone, N. B. (2013). Collaboration as a form of professional development: Improving learning for faculty and students. College Teaching, 61(1), $30-37$.

Dorman, J. P. (2003). Cross-national validation of the What Is Happening In this Class? (WIHIC) questionnaire using confirmatory factor analysis. Learning Environments Research, 6, 231-245. 
Dorman, J. P. (2008). Use of multitrait-multimethod modelling to validate actual and preferred forms of the What Is Happening In this Class? questionnaire. Learning Environments Research, 11, 179-197.

DuFour, R., DuFour, R., Eaker, R., \& Many, T. (2006). Learning by doing: A handbook for professional learning communities at work. Bloomington, IN: Solution Tree.

Earle, J. E., \& Fraser, B. J. (2018). Evaluating online resources in terms of classroom environment and student attitudes in middle-grades mathematics. Learning Environments Research, 20(3), 339-364.

Evans, L. (2014). Leadership for professional development and learning: Enhancing our understanding of how teachers develop. Cambridge Journal of Education, 44(2), 179198.

Fraser, B. J. (1981). Using environmental assessments to make better classrooms. Journal of Curriculum Studies, 13(2), 131-144.

Fraser, B. J. (1990). Individualised Classroom Environment Questionnaire. Melbourne, Australia: Australian Council for Educational Research.

Fraser, B. J. (2012). Classroom learning environments: Retrospect, context and prospect. In B. J., Fraser, K. G. Tobin, and C. J. McRobbie (Eds.), Second international handbook of science education (pp. 1191-1232). New York: Springer.

Fraser, B. J. (2014). Classroom learning environments: Historical and contemporary perspectives. In N. G. Lederman and S. K. Abell (Eds.), Handbook of research on science education, Volume II (pp. 104-119). New York: Routledge.

Fraser, B.J. (2019). Milestones in the evolution of the learning environments field. In D.B. Zandvliet and B.J. Fraser (Eds.), Thirty years of learning environments (pp. 1-19). Leiden, the Netherlands: Brill | Sense. 
Fraser, B. J., \& Aldridge, J. M. (2017). Improving classrooms through assessment of learning environments. In J.P. Bakken (Ed.), Classrooms Volume 1: Assessment practices for teachers and student improvement strategies (pp. 91-107). New York: Nova.

Fraser, B. J., \& Butts, W. L. (1982). Relationship between perceived levels of classroom individualization and science-related attitudes. Journal of Research in Science Teaching, 19, 143-154.

Fraser, B.J., \& Fisher, D.L. (1982). Predicting students' outcomes from their classroom psychosocial environment. American Educational Research Journal, 19, 498-518.

Fraser, B. J., \& Rentoul, A. J. (1982). Relationship between school-level and classroom-level environment. Alberta Journal of Educational Research, 28, 212-225.

Fullan, M. (1999). Change forces: The sequel. London: Falmer Press.

Fullan, M. (2001). Leading in a culture of change. San Francisco: Jossey-Bass.

Fullan, M. (2006). The new meaning of educational change ( $3^{\text {rd }}$ ed.). New York: Teachers College Press.

Galini, R., \& Efthymia, P. (2010). A collaborative action research project in the kindergarten: Perspectives and challenges for teacher development through internal evaluation processes. New Horizons in Education, 58(2), 18-33.

Girvan, C., Conneely, C., \& Tangney, B. (2016). Extending experiential learning in teacher professional development. Teaching and Teacher Education, 58, 129-139.

Glanz, J. (2016). Action research by practitioners: A case study of a high school's attempt to create transformational change. Journal of Practitioner Research, 1(1), 1-23.

Griffin, P., \& Smith, P. (1997). Hindering and facilitating factors in OBE. Canberra: Australian Curriculum Studies Association.

Hahs-Vaughn, D. L., \& Yanowitz, K. L. (2009). Who is conducting teacher research? The Journal of Educational Research, 102(6), 415-424. 
Helsing, D., Howell, A., Kegan, R., \& Lahey, L. (2008). Putting the "development" in professional development: Understanding and overturning educational leaders' immunities to change. Harvard Educational Review, 78, 437-465.

Herbert, S., \& Rainford, M. (2014). Developing a model for continuous professional development by action research. Professional Development in Education, 40, $243-$ 264.

Hewitt, R., \& Little, M. (2005). Leading action research in schools. Daytona Beach, FL: State of Florida, Department of State.

Hijzen, D., Boekaerts, M., \& Vedder, P. (2007). Exploring the links between students' engagement in cooperative learning, their goal preferences and appraisals of instructional conditions in the classroom. Learning and Instruction, 17, 673-687.

Hine, G. S. (2013). The importance of action research in teacher education research. Issues in Educational Research, 23(2), 151-163.

Hobbs, R., \& Coiro, J. (2016). Everyone learns from everyone: Collaborative and interdisciplinary professional development in digital literacy. Journal of Adolescent \& Adult Literacy, 59, 623-629.

Holloway, K., \& Long, R. (2006). Teacher development and school improvement: The use of 'shared practice groups' to improve teaching in primary schools. Journal of In-service Education, 24(3), 535-545.

Hu, Q.-L., Torres, M.N., \& Feng, S.-J. (2019). Collaborative action research for preparing teachers as reflective practitioners. Systemic Practice and Action Research, 32(4), 411-427. doi:http://dx.doi.org/10.1007/s11213-018-9461-z

Hunt, D. E. (1975). Person-environment interaction: A challenge found wanting before it was tried. Review of Educational Research, 45, 209-230. 
Johnson, D.W., Johnson, R.T., \& Smith, K. (2007). The state of cooperative learning in postsecondary and professional settings. Educational Psychology Review, 19, 15-29.

Kasi, F. (2010). Collaborative action research: An alternative model for EFL teacher professional development in Pakistan. Asian EFL Journal, 12(3), 98-117.

Kelly, N., \& Antonio, A. (2016). Teacher peer support in social network sites. Teaching and Teacher Education, 56, 138-149.

Kemmis, S., \& McTaggart, R. (1988). The action research planner. Geelong: Deakin University Press.

Khine, M.S., Fraser, B.J., Afari. E., Oo, Z., \& Kyaw, T.T. (2018). Students' perceptions of the learning environment in tertiary science classrooms in Myanmar. Learning Environments Research, 21(1), 135-152.

Kijkuakul, S. (2019). Professional changes of primary science teachers: Experience on collaborative action research in Thailand. Asia-Pacific Science Education, 5, 1-22. doi:http://dx.doi.org/10.1186/s41029-019-0030-2

Killen, R. (2001). Outcomes-based education: Principles and possibilities. Online: http://www.acel.org.au/affiliates/new/conference01/ts_1.html.

Kim, H. B., Fisher, D. L., \& Fraser, B. J. (1999). Assessment and investigation of constructivist science learning environments in Korea. Research in Science and Technological Education, 17, 239-249.

Koh, N. K., \& Fraser, B. J. (2014). Learning environment associated with use of mixed mode delivery model among secondary business studies students in SIngapore. Learning Environments Research, 17(2), 157-171.

Koul, R. B., Fisher, D. L., \& Shaw, T. (2011). An application of the TROFLEI in secondaryschool science classes in New Zealand. Research in Science and Technological Education, 29(2), 147-167. 
Lampi, J. P., Dimino, R. K., \& Taylor, J. S. (2015). Connecting practice \& research: A shared growth professional development model. Journal of Developmental Education, 39(1), $32-33$.

Leithwood, K., \& Day, C. (2008). The impact of school leadership on pupil outcomes. School Leadership \& Management, 28(1), 1-4.

Leo, U., \& Wickenberg, P. (2013). Professional norms in school leadership: Change efforts in implementation of education for sustainable development. Journal of Educational Change, 14(4), 403-422.

Levin, B. B., \& Rock, T. T. (2003). The effects of collaborative action research on preservice and inservice teacher partners in professional development school. Journal of Teacher Education, 54, 135-149.

Lewin, K. (1936). Principles of topological psychology. New York: McGraw.

Lightburn, M., \& Fraser, B. J. (2007). Classroom environment and student outcomes among students using anthropometry activities in high school science. Research in Science and Technological Education, 25, 153- 166.

Lin, M.C., \& Burbules, N.C. (1993). Construction of knowledge and group learning. In K. Tobin (Ed.), The practice of constructivism in science education (pp. 91-119). Washington, DC: AAAS Press.

Macià, M., \& García, I. (2016). Informal online communities and networks as a source of teacher professional development: A review. Teaching and Teacher Education, 55, 291-307.

Magen-Nagar, N., \& Steinberger, P. (2017). Characteristics of an innovative learning environment according to students' perceptions: Actual versus preferred. Learning Environments Research, 20(3), 307-323. 
Manesi, S., \& Betsi, S. (2013). Collaborative action research projects: The role of communities of practice and mentoring in enhancing teachers' continuing professional development. Action Researcher in Education, 4, 109-121.

McLeskey, J., \& Waldron, N. (2006). Comprehensive school reform and inclusive schools: Improving schools for all students. Theory into Practice, 45, 269-278.

McTaggart, R. (1997). Reading the collection. In R. McTaggart (Ed.), Participatory action research (pp. 1-12). Albany, NY: SUNY Press.

Moos, R. H., \& Trickett. E. J. (1974). Classroom Environment Scale manual. Palo Alto, CA: Consulting Psychologists Press.

Mourshed, M., \& Barber, M (2007). How the world's best-performing school systems come out on top. http://www.mckinseyonsociety.com

Mug`alog`lu, E. Z., \& Dog`anca, Z. (2009). Fulfilling the "missing link" between university and authentic workplace in teacher training. Journal of Workplace Learning, 21(6), 455-464.

Murray, H. A. (1938). Explorations in personality. New York: Oxford University Press.

Ngcoza, K., \& Southwood, S. (2015). Professional development networks: From transmission to co-construction. Perspectives in Education, 33(1), 1-6.

Nix, R. K., Fraser, B. J., \& Ledbetter, C. E. (2005). Evaluating an integrated science learning environment using the Constructivist Learning Environment Survey. Learning Environments Research, 8, 109-133.

O’Donovan, B., Price, M., \& Rust. C. (2004). Know what I mean?: Enhancing student understanding of assessment standards and criteria. Teaching in Higher Education, 9, 325-335.

OECD (Organisation for Economic Co-operation and Development). (2011). Building a highquality teaching profession: Lessons from around the world. Paris: OECD. 
Partin, M.L., \& Haney, J.J. (2012). The CLEM model: Path analysis of the mediating effects of attitudes and motivational beliefs on the relationship between perceived learning environment and course performance in an undergraduate non-major biology course. Learning Environments Research, 15, 103-123.

Pellerin, M. (2011). University-school collaborative action research as an alternative model for professional development through AISI. Retrieved July 25, 2016, from uleth.ca: http://www.uleth.ca/education/sites/education/files/AISI\%20V1\%201\%201\%20Fall\% 202011.pdf

Pellerin, M., \& Paukner, F. I. (2015). Becoming reflective and inquiring teachers: Collaborative action research for in-service Chilean teachers. Revista Electrónica de Investigación Educativa, 17(3), 13-27.

Peterson, S. S., Swartz, L., Bodnar, S., McCaigg, G., Ritchie, S., Dawson, R., et al. (2008). Collaborative action research supporting teachers' professional development as exemplified by one teacher team's action research on a study of silent reading. Retrieved July 1, 2016, from oar.nipissingu.ca: http://oar.nipissingu.ca/PDFS/V1113.pdf

Reeves, D. B. (2007). Leading to change: How do you change school culture? Educational Leadership, 64, 92-94.

Reeves, D. B. (2008). Reframing teacher leadership to improve your school. Alexandria, VA: Association for Supervision and Curriculum Development.

Rennie, L.J. (2004). Equity and the inclusive science curriculum. In G. Venville \& V. Dawson (Eds.), The art of teaching science (pp. 178-193). Sydney, Australia: Allen \& Unwin. 
Rennie, L.J. (2005). Equity in science teaching and learning: The inclusive science curriculum. In S. Alsop, L. Benze, \& E. Pedretti (Eds.), Analysing exemplary science teaching (pp. 183-192). Columbus, OH: Open University Press.

Rock, T. C., \& Levin, B. B. (2002). Collaborative action research projects: Enhancing preservice teacher development. Teacher Education Quarterly 29 (1), 7-21

Ross, J. A., \& Bruce, C. D. (2007). Professional development effects on teacher efficacy: Results of a randomized field trial. The Journal of Educational Research, 101(1), 5060.

Ross, J. A., \& Bruce, C. D. (2012). Evaluating the impact of collaborative action research on teachers: A quantitative approach. Teacher Development, 16(4), 537-561.

Schriesheim, C. A., Eisenbach, R. J., \& Hill, K. D. (1991). The effect of negation and polar opposite item reversals on questionnaire reliability and validity: An experimental investigation. Educational and Psychological Measurement, 51(1), 67-78.

Schriesheim, C. A., \& Hill, K. D. (1981). Controlling acquiescence response bias by item reversals: The effect on questionnaire validity. Educational and Psychological Measurement, 41(4), 1101-1114.

Simeon, J. (2015). A reflexive account on my positionality in a collaborative action research project in a Seychelles secondary school. Qualitative Research Journal, 15(1), 2-19.

Skordi, P., Fraser, B.J. (2019). Validity and use of the What Is Happening In this Class? (WIHIC) questionnaire in university business statistics classrooms, Learning Environments Research, 22(2), 275-295.

Smith, I. (2005). Continuing professional development and workplace learning: Resistance to change - Recognition and response. Library Management, 26(8/9), 519-522.

Spady, W. (1993). Outcomes-based education. Canberra: Australian Curriculum Studies Association. 
Spady, W. (1994). Outcome-based education: Critical issues and answers. Arlington, VA: American Association of School Administrators.

Stern, G. G. (1970). People in context: Measuring person-environment congruence in education and industry. New York: Wiley.

Tan, I.G.C., Sharan, S., \& Lee, C.K.E. (2007). Group investigation effects on achievement, motivation, and perceptions of students in Singapore. Journal of Educational Research, 100, 142-154.

Taylor, P.C., \& Campbell-Williams, M. (1993). Discourse towards balanced rationality in the high school mathematics classroom: Ideas from Habermas's critical theory. In J.A. Malone, \& P.C.S. Taylor (Eds.), Constructivist interpretations of teaching and learning mathematics (Proceeding of Topic Group 10 at the Seventh International Congress on Mathematical Education; pp. 135-148). Perth, Western Australia: Curtin University of Technology.

Taylor, P. C., Fraser, B. J., \& Fisher, D. L. (1997). Monitoring constructivist classroom learning environments. International Journal of Educational Research, 27, 293-302.

van Maanen, J. (1988). Tales of the field: On writing ethnography. Chicago: University of Chicago.

Walberg, H. J., \& Anderson, G. J. (1968). Classroom climate and individual learning. Journal of Educational Psychology, 59, 414-419.

Waldron, N. L., \& McLeskey, J. (2010). Establishing a collaborative school culture through comprehensive school reform. Journal of Educational and Psychological Consultation, 20, 58-74.

West, C. (2011). Action research as a professional development activity. Arts Education Policy Review, 112, 89-94. 
Welch, A. G., Cakir, M., Peterson, C. M., \& Ray, C. M. (2012). A cross-cultural validation of the Technology-Rich Outcomes-Focused Learning Environment Inventory (TROFLEI) in Turkey and the USA. Research in Science and Technological Education, 30(1), 49-63.

Wubbels, Th., \& Levy, J. (Eds.). (1993). Do you know what you look like: Interpersonal relationships in education? London: Falmer Press.

Yang, J.E. (2019). Science teachers taking their first steps toward teaching socioscientific issues through collaborative action research. Research in Science Education, 49(1), 51-71. doi:http://dx.doi.org/10.1007/s11165-017-9614-6

Yin, R.K. (2011). Qualitative research from start to finish. New York: Guilford Press.

Zaragoza, J. M., \& Fraser, B. J. (2017). Field-study classrooms as positive and enjoyable learning environments. Learning Environments Research, 20, 1-20. 


\section{List of figures}

Fig. 1 Illustration of side-by-side response format for actual and preferred CCQ items

Fig. 2 Mean actual and preferred scores for students' perceptions of the learning environment for Lily's class for the pretest

Fig. 3 Mean actual and preferred scores for students' perceptions of the learning environment for Lily's class for the posttest 


\begin{tabular}{|c|c|c|c|c|c|c|c|c|c|}
\hline \multirow[b]{2}{*}{ Equity } & \multicolumn{4}{|c|}{ ACTUAL } & \multicolumn{5}{|c|}{ PREFERRED } \\
\hline & $\begin{array}{l}\text { Almost Seldom } \\
\text { Never }\end{array}$ & $\begin{array}{l}\text { Some } \\
\text { times }\end{array}$ & Often & $\begin{array}{l}\text { Almost } \\
\text { Always }\end{array}$ & Almost & Seldom & $\begin{array}{l}\text { Some } \\
\text { times }\end{array}$ & Often & $\begin{array}{l}\text { Almost } \\
\text { Always }\end{array}$ \\
\hline $\begin{array}{l}\text { I get the same amount of help from the teacher as do other } \\
\text { students. }\end{array}$ & 2 & 3 & 4 & 5 & 1 & 2 & 3 & 4 & 5 \\
\hline
\end{tabular}

Fig. 1 


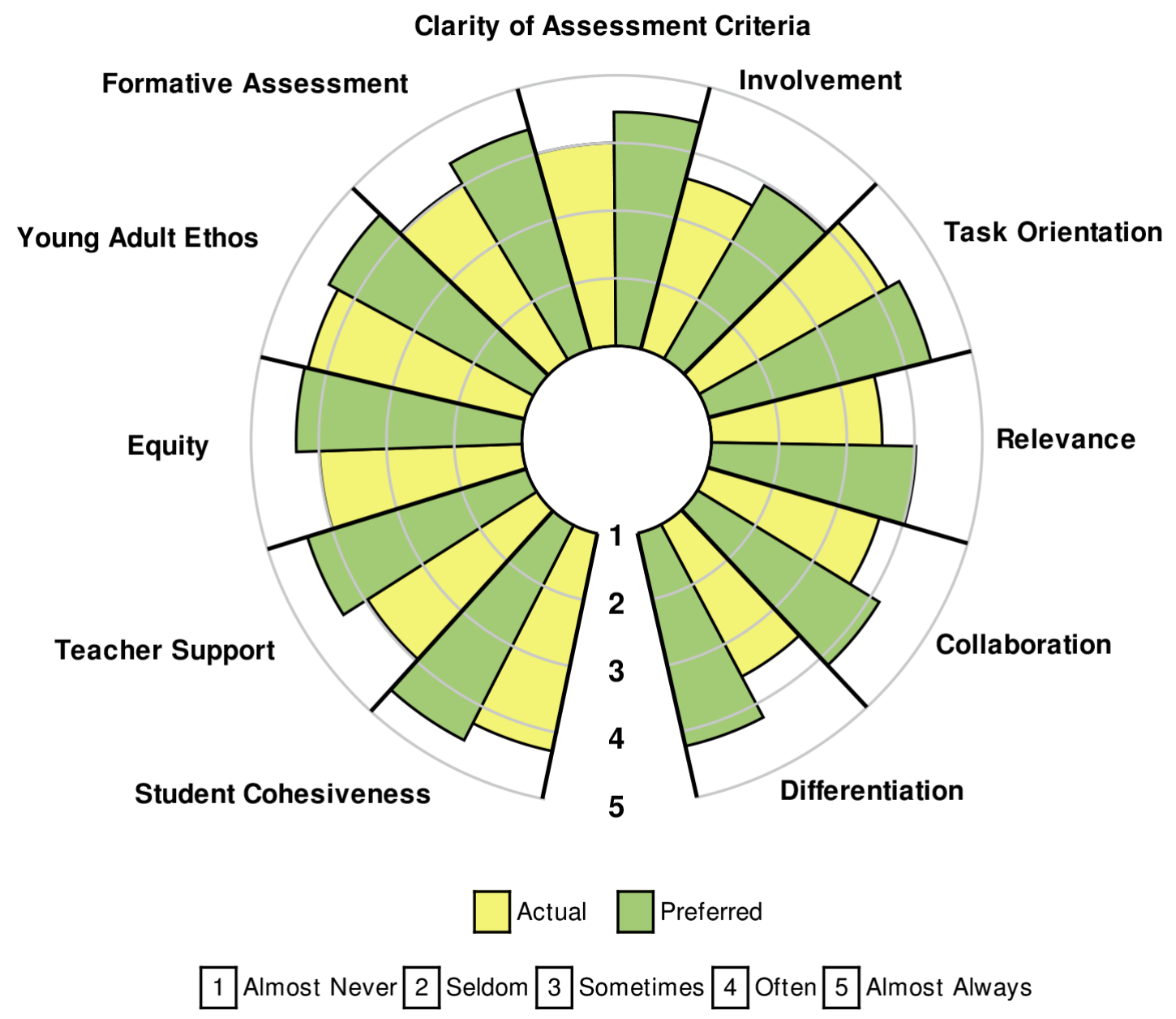

Fig. 2 


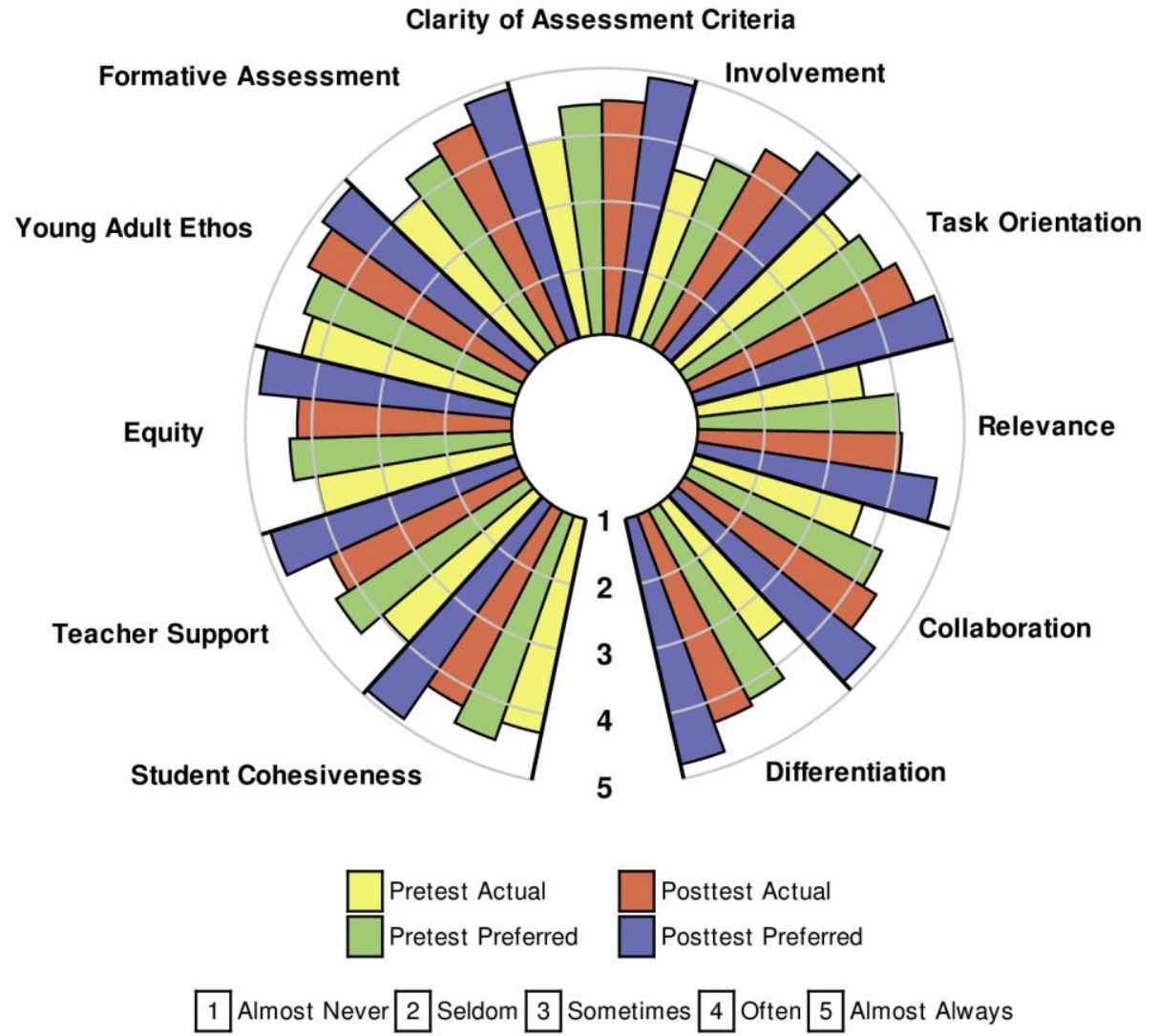

Fig. 3 
Table 1. Original source, scale description and alpha reliability coefficient for each CCQ scale

\begin{tabular}{|c|c|c|c|}
\hline Scale & Original source & Description & $\begin{array}{l}\text { Alpha } \\
\text { reliability }\end{array}$ \\
\hline Student Cohesiveness & WIHIC & $\begin{array}{l}\text { The extent to which ... } \\
\text {...students know, help and are } \\
\text { supportive of one another. }\end{array}$ & 0.87 \\
\hline Teacher Support & WIHIC & $\begin{array}{l}\text {..the teacher helps, befriends, trusts } \\
\text { and is interested in students. }\end{array}$ & 0.87 \\
\hline Equity & WIHIC & $\begin{array}{l}\text {...students are treated equally by the } \\
\text { teacher. }\end{array}$ & 0.92 \\
\hline Young Adult Ethos & TROFLEI & $\begin{array}{l}\text {...teachers give students responsibility } \\
\text { and treat them as young adults. }\end{array}$ & 0.88 \\
\hline Formative Assessment & COLES & $\begin{array}{l}\text {..students feel that the assessment } \\
\text { tasks given to them make a positive } \\
\text { contribution to their learning. }\end{array}$ & 0.88 \\
\hline Assessment Criteria & COLES & $\begin{array}{l}\ldots \text { the assessment criteria are explicit } \\
\text { so that the basis for judgments is clear } \\
\text { and public }\end{array}$ & 0.94 \\
\hline Involvement & WIHIC & $\begin{array}{l}\text {...students have attentive interest, } \\
\text { participate in discussions, ask } \\
\text { questions and share ideas. }\end{array}$ & 0.92 \\
\hline Task Orientation & WIHIC & $\begin{array}{l}\text {...it is important to complete activities } \\
\text { planned and to stay on the subject } \\
\text { matter. }\end{array}$ & 0.91 \\
\hline Personal Relevance & CLES & $\begin{array}{l}\text {...subject is relevant to students' } \\
\text { everyday out-of-school experiences. }\end{array}$ & 0.94 \\
\hline Collaboration & WIHIC & $\begin{array}{l}\text {...students cooperate with one another } \\
\text { on learning tasks. }\end{array}$ & 0.91 \\
\hline Differentiation & ICEQ & $\begin{array}{l}\text {..teachers cater for students } \\
\text { differently on the basis of ability, rates } \\
\text { of learning and interests. }\end{array}$ & 0.93 \\
\hline \multicolumn{4}{|c|}{ WIHIC What Is Happening In this Class? } \\
\hline Constructivist-Ori & $\begin{array}{l}\text { tcomes-Focused Lea } \\
\text { ed Learning Environ }\end{array}$ & $\begin{array}{l}\text { Environment Inventory } \\
\text { Survey }\end{array}$ & \\
\hline CLES Constructivist Lear & ng Environment Surve & & \\
\hline ICEQ Individualised Clas & oom Environment Que & onnaire & \\
\hline
\end{tabular}


Table 2 Average item mean, average item standard deviation and anova result for differences between 2012, 2013 and 2014 groups for each classroom environment scale

\begin{tabular}{|c|c|c|c|c|c|c|c|}
\hline \multirow[t]{2}{*}{ Scale } & \multicolumn{3}{|c|}{$\begin{array}{c}\text { Average item } \\
\text { mean }\end{array}$} & \multicolumn{3}{|c|}{$\begin{array}{c}\text { Average item } \\
\text { standard deviation }\end{array}$} & \multirow{2}{*}{$\begin{array}{l}\begin{array}{l}\text { Difference } \\
\text { between } \\
\text { groups }\end{array} \\
\text { F }\end{array}$} \\
\hline & $\begin{array}{l}2012 \\
\text { group }\end{array}$ & $\begin{array}{l}2013 \\
\text { group }\end{array}$ & $\begin{array}{c}2014 \\
\text { group }\end{array}$ & $\begin{array}{l}2012 \\
\text { group }\end{array}$ & $\begin{array}{l}2013 \\
\text { group }\end{array}$ & $\begin{array}{l}2014 \\
\text { group }\end{array}$ & \\
\hline Student Cohesiveness & 4.23 & 4.15 & 4.20 & 0.60 & 0.66 & 0.74 & 2.66 \\
\hline Teacher Support & 4.01 & 4.03 & 4.10 & 0.78 & 0.79 & 0.89 & 2.77 \\
\hline Equity & 4.21 & 4.24 & 4.19 & 0.79 & 0.78 & 0.86 & 0.83 \\
\hline Young Adult Ethos & 4.15 & 4.27 & 4.31 & 0.79 & 0.78 & 0.86 & $8.48 * *$ \\
\hline Formative Assessment & 3.92 & 4.04 & 4.13 & 0.83 & 0.75 & 0.87 & $10.84 * *$ \\
\hline Clarity of Assessment & 3.90 & 4.01 & 4.13 & 0.77 & 0.72 & 0.85 & $16.07 * *$ \\
\hline Involvement & 3.40 & 3.50 & 3.68 & 0.92 & 0.92 & 1.02 & $16.46^{* *}$ \\
\hline Task Orientation & 4.13 & 4.23 & 4.27 & 0.70 & 0.95 & 0.76 & $6.87 * *$ \\
\hline Personal Relevance & 3.40 & 3.54 & 3.68 & 0.91 & 0.96 & 1.09 & $13.31 * *$ \\
\hline Collaboration & 3.78 & 3.68 & 3.82 & 0.78 & 0.89 & 0.91 & $7.01 * *$ \\
\hline Differentiation & 3.37 & 3.53 & 3.73 & 0.84 & 0.85 & 0.99 & $27.66 * *$ \\
\hline
\end{tabular}

$N=498$ student responses in 2012, 1252 student responses in 2013 and 923 student responses in 2014.

$* * p<0.01$ 
Table 3 Effect size and Tukey's HSD multiple comparison for statistical significance of difference between each pair of year groups for classroom environment scales

\begin{tabular}{lccc}
\hline Scale & \multicolumn{3}{c}{ Effect size \& Tukey HSD } \\
\cline { 2 - 4 } & $2012 / 2013$ groups & $2013 / 2014$ groups & $2012 / 2014$ groups \\
\hline Student Cohesiveness & -0.12 & 0.07 & -0.02 \\
Teacher Support & 0.03 & 0.08 & 0.11 \\
Equity & 0.04 & -0.06 & 0.02 \\
Young Adult Ethos & $0.15^{*}$ & 0.04 & $0.19^{*}$ \\
Formative Assessment & $0.15^{*}$ & $0.11^{*}$ & $0.25^{*}$ \\
Clarity of Assessment & $0.15^{*}$ & $0.15^{*}$ & $0.28^{*}$ \\
Involvement & 0.11 & $0.19^{*}$ & $0.29^{*}$ \\
Task Orientation & $0.12^{*}$ & 0.05 & $0.19^{*}$ \\
Personal Relevance & $0.15^{*}$ & $0.14^{*}$ & $0.28^{*}$ \\
Collaboration & -0.12 & $0.16^{*}$ & 0.05 \\
Differentiation & $0.19^{*}$ & $0.22^{*}$ & $0.39^{*}$ \\
\hline
\end{tabular}

$* p<0.05, * * p<0.01$

$N=498$ student responses in 2012, 1252 student responses in 2013 and 923 student responses in 2014.

Effect size is the difference in means expressed in standard deviation units and was calculated using the formula: $d=\left(M_{1^{-}}\right.$-

$\left.\mathrm{M}_{2}\right) / \sqrt{ }\left[\left(\sigma_{1}^{2}+\sigma_{2}{ }^{2}\right) / 2\right]$ 